\title{
USO DE ANTIBIÓTICOS PARA O CONTROLE DE BACTÉRIAS ENDÓGENAS VISANDO À MICROPROPAGAÇÃO DA FIGUEIRA ${ }^{1}$
}

\author{
EDNAMAR GABRIELA PALU' ${ }^{2}$, LUIZ DE SOUZA CORREA ${ }^{3}$, \\ ALINE NAMIE SUZUKI ${ }^{4}$, APARECIDA CONCEIÇÃO BOLIANI ${ }^{5}$
}

\begin{abstract}
RESUMO- A descontaminação dos explantes é um dos princípios básicos para o sucesso da cultura de tecidos. Um dos problemas diagnosticados na propagação in vitro da figueira, através de gemas apicais, é a contaminação endógena dos explantes por bactérias. Este trabalho teve como objetivo avaliar a eficiência de alguns antibióticos em meio de cultura para o controle de bactérias endógenas em gemas apicais de figueira. Foram avaliados os seguintes tratamentos: $\mathrm{T}_{1}$ (sem adição de antibiótico); $\mathrm{T}_{2}\left(30 \mathrm{mg} \mathrm{L}^{-1}\right.$ de cloranfenicol); $\mathrm{T}_{3}$ (250 $\mathrm{mg} \mathrm{L}^{-1}$ de ampicilina sódica); $\mathrm{T}_{4}\left(500 \mathrm{mg} \mathrm{L}^{-1}\right.$ de ácido nalidícico); $\mathrm{T}_{5}\left(150 \mathrm{mg} \mathrm{L}^{-1}\right.$ de cefalotina sódica); $\mathrm{T}_{6}$ (500 $\mathrm{mg} \mathrm{L}^{-1}$ de tetraciclina), e $\mathrm{T}_{7}$ (400 $\mathrm{mg} \mathrm{L}^{-1}$ de norfloxacina). Após coletados em campo, os segmentos de ramos contendo as gemas foram colocados em recipiente com água corrente. Posteriormente, as gemas apicais foram imersas em álcool etílico a $70 \%$ e hipoclorito de sódio a $2,5 \%$. Todo procedimento de desinfestação externa dos explantes foi realizado em câmara de fluxo laminar. Os explantes foram inoculados em tubos de ensaio contendo $15 \mathrm{~mL}$ de meio básico MS suplementado, após a autoclavagem, com as doses de antibióticos de acordo com os tratamentos estabelecidos. Após a inoculação, os explantes foram mantidos em sala de crescimento por quatro dias no escuro e, em seguida, sob fotoperíodo de 16 horas de luz branca fria e irradiância de $25 \mu \mathrm{mol} \mathrm{m} \mathrm{s}{ }^{-1}$, na temperatura de $22 \pm 3^{\circ} \mathrm{C}$. A assepsia realizada externamente nos explantes foi suficiente para o controle de contaminação fúngica, e a adição de antibióticos ao meio, após autoclavagem, foi eficiente para o controle de bactérias endógenas, cujo antibiótico ampicilina sódica proporcionou mais de $90 \%$ de explantes sobreviventes.
\end{abstract}

Termos para indexação: Ficus carica L., gema apical, assepsia, in vitro.

\section{USE OF ANTIBIOTICS FOR THE CONTROL OF ENDOGENOUS BACTERIA AIMING THE MICROPROPAGATION OF FIG TREES}

\begin{abstract}
The explants decontamination is one of the basic principles for the success of Tissue Culture. One of the problems diagnosed in vitro propagation using fig shoot tips is the endogenous contamination of the explants by bacteria. This study aimed to verify the efficiency of the addition of some antibiotics to the culture medium to control potential endogenous bacteria in fig apical buds. It was evaluated the following antibiotics added to the culture medium: $\mathrm{T}_{1}$ (without antibiotic), $\mathrm{T}_{2}\left(30 \mathrm{mg} \mathrm{L}^{-1}\right.$ of chloramphenicol), $\mathrm{T}_{3}(250$ $\mathrm{mg} \mathrm{L}^{-1}$ of ampicillin sodium), $\mathrm{T}_{4}\left(500 \mathrm{mg} \mathrm{L}^{-1}\right.$ of nalidicic acid), $\mathrm{T}_{5}\left(150 \mathrm{mg} \mathrm{L}^{-1}\right.$ of cephalothin sodium), $\mathrm{T}_{6}$ (500 mg L-1 of tetracycline) and $\mathrm{T}_{7}$ (400 $\mathrm{mg} \mathrm{L}^{-1}$ of norfloxacin). Once collected in the field the segments of branches containing the gems were placed in a container with water and subsequently, the apical buds were immersed in $70 \%$ ethyl alcohol and sodium hypochlorite $2.5 \%$. All external disinfection procedure of the explants was conducted in a laminar flow chamber. The explants were inoculated in test tubes containing $15 \mathrm{~mL}$ of enriched MS basal medium and with doses of antibiotics according to pre-established treatments. After inoculation, the explants were kept in a growth chamber for four days in the dark and then under photoperiods of 16 hours of cold white light and irradiance of $25 \mu \mathrm{mol} \mathrm{m} \mathrm{s}{ }^{-1}$ at $22 \pm 3{ }^{\circ} \mathrm{C}$. The results showed that the explants external disinfection was sufficient to control fungal contamination and the addition of antibiotics to the medium after autoclaving was effective to control of endogenous bacteria. The best result was obtained with the antibiotic ampicillin sodium which provided more than $90 \%$ of survivor explants.
\end{abstract}

Index terms: Ficus carica L., apical buds, aseptic, in vitro.

\footnotetext{
${ }^{1}$ (Trabalho 130-10). Recebido em: 24-05-2010. Aceito para publicação em: 19-10-2010. Parte da tese, apresentada pelo primeiro autor, a Universidade Estadual Paulista "Júlio de Mesquita Filho"(UNESP), campus de Ilha Solteira -SP, como um dos requisitos do curso de Doutorado em Agronomia, especialidade Sistemas de Produção.

${ }^{2} E_{n g}$ a.-Agra ., Ms., Doutoranda em Agronomia UNESP, Campus de Ilha Solteira - SP, E-mail: gapalu28@hotmail.com.

${ }^{3}$ Eng $^{\circ}$. Agr ${ }^{\circ}$., Dr., prof. do Departamento de Fitotecnia, Tecnologia de Alimentos e Sócio Economia/UNESP, Campus de Ilha Solteira -SP, E-mail: 1correa@agr.feis.unesp.br.

${ }^{4}$ Graduanda em Agronomia UNESP, Campus de Ilha Solteira - SP, E-mail: namie_suzuki@hotmail.com.

${ }^{5} E_{n g}{ }^{a}$.Agra ${ }^{\text {. }}$, Dra., profa. do Departamento de Fitotecnia, Tecnologia de Alimentos e Sócio Economia/UNESP, Campus de Ilha Solteira -SP, E-mail: boliani@agr.feis.unesp.br
} 


\section{INTRODUÇÃO}

O Brasil destaca-se como o maior produtor de figo da América do Sul, ocupa a $11^{\text {a }}$ colocação entre os principais produtores mundiais e é o segundo exportador de figo in natura no mundo, superado apenas pela Turquia (FOOD AGRICULTURAL ORGANIZATION, 2008).

A estaquia é o método de propagação mais utilizado na cultura da figueira (Ficus carica L.) (FACHINELLO et al., 2005). Mesmo proporcionando elevados percentuais de enraizamento, a estaquia acarreta intenso uso de mão de obra, contribuindo para a elevação do custo da muda, além de disseminar patógenos, como vírus, fungos e nematoides, reduzindo a qualidade final da muda.

A utilização de mudas de alta qualidade é um dos requisitos mais importantes para implantação de pomares com maior longevidade e elevada produtividade. Em pomares comerciais, deve-se buscar uniformidade de plantas e principalmente dos frutos, de modo que eles estejam embasados em plantas originadas por processos vegetativos, sendo que um deles pode ser a micropropagação (MANICA et al., 2003).

A propagação in vitro pode auxiliar na produção eficiente de mudas de figueira com alta qualidade fitossanitária e genética. De acordo com Paiva (1998), esta técnica vem sendo aplicada com sucesso para obtenção de mudas sadias em grande número de espécies economicamente importantes ou com dificuldades de propagação, realizando avanços importantes nas áreas de genética, fisiologia e fitopatologia. No entanto, para a cultura da figueira, são escassos os trabalhos realizados in vitro, conhecendo-se pouco sobre o comportamento da planta, e principalmente como é realizado o estabelecimento desta. Gerra e Costa (1987) e Barbosa et al. (1992) relatam que a planta é estabelecida in vitro através da inoculação de meristemas ao meio de cultura, mas nenhum dos autores cita a percentagem de explantes sobreviventes após a inoculação. Brum (2001) e Fráguas (2003) descrevem sobre a micropropagação da figueira, mas em ambos os trabalhos realizados pelos autores utilizam-se plantas já estabelecidas in vitro.

$\mathrm{Na}$ cultura de tecidos, são essenciais o controle e a prevenção da contaminação microbiana, pois o meio de cultura proporciona um ambiente favorável para o crescimento de microrganismos, como bactérias, leveduras e fungos (DANTAS et al., 2002), constituindo-se nas principais causas de perdas de material vegetal.

Um dos problemas da micropropagação da figueira através de gemas apicais é a alta taxa de contaminação, principalmente por bactérias endógenas. Os contaminantes, especialmente as bactérias endógenas, impõem consideráveis limitações mesmo na fase de introdução in vitro. Quando a contaminação por microrganismos é exógena, a possibilidade de controle dos principais agentes contaminantes (fungos e bactérias) é considerável. Quando a contaminação é endógena, as consequências podem ser limitantes, podendo haver perda de tempo, de recursos financeiros e de material genético (SOUZA et al., 2006). Os antibióticos usados para o controle de bactérias podem possuir ação bacteriostática, e não bactericida, serem fitotóxicos e favorecerem alterações nas respostas morfogenéticas (GRATTAPAGLIA; MACHADO, 1990).

Diversas pesquisas têm sido realizadas para a prevenção ou eliminação dos contaminantes do cultivo in vitro de plantas, desde o desenvolvimento de protocolos de assepsia, cuidados com as plantasmatrizes, até o uso de produtos antimicrobianos, adicionados ao meio de cultura (PEREIRA et al., 2009). Biasi (1995) testou a adição, ao meio de cultura, de diferentes doses dos antibióticos ácido nalíxico, cloranfenicol e estreptomicina, para o controle in vitro de bactérias, em segmentos nodais e discos foliares de abacateiro. Pereira et al. (2003) observaram que a adição dos antibióticos ampicilina, cloranfenicol, estreptomicina e tetraciclina, em concentrações que variam de 32 a $256 \mathrm{mg} \mathrm{L}^{-1}$, inibem o crescimento de bactérias contaminantes na cultura de tecidos da batata (Solanum tuberosum L.).

Este trabalho teve por objetivo avaliar a eficiência da descontaminação de gemas apicais de figueira, utilizando-se de diferentes antibióticos, para seu estabelecimento in vitro.

\section{MATERIAL E MÉTODOS}

O trabalho foi conduzido no Laboratório de Biotecnologia pertencente à Faculdade de Engenharia da UNESP - Câmpus de Ilha Solteira - SP, em maio de 2009. Foram utilizadas gemas apicais de figueira cv. Roxo de Valinhos, seleção Gigante, procedentes da coleção do campo experimental da Fazenda de Ensino, Pesquisa e Extensão da Faculdade de Engenharia da UNESP - Câmpus de Ilha Solteira, localizada em Selvíria - MS.

$\mathrm{O}$ experimento foi constituído da adição de antibióticos ao meio de cultura. $\mathrm{O}$ delineamento experimental foi o inteiramente casualizado, com sete tratamentos, cinco repetições e sete gemas por repetição. Os tratamentos foram: $\mathrm{T}_{1}$ (sem adição de antibiótico); $\mathrm{T}_{2}$ (30 $\mathrm{mg} \mathrm{L}^{-1}$ de cloranfenicol); $\mathrm{T}_{3}(250$ $\mathrm{mg} \mathrm{L}{ }^{-1}$ de ampicilina sódica $) ; \mathrm{T}_{4}\left(500 \mathrm{mg} \mathrm{L}^{-1}\right.$ de ácido 
nalidícico); $\mathrm{T}_{5}$ (150 $\mathrm{mg} \mathrm{L}^{-1}$ de cefalotina sódica); $\mathrm{T}_{6}$ (500 $\mathrm{mg} \mathrm{L}^{-1}$ de tetraciclina), e $\mathrm{T}_{7}\left(400 \mathrm{mg} \mathrm{L}^{-1}\right.$ de norfloxacina). Os antibióticos e as doses testadas foram estabelecidos de acordo com os trabalhos de Pereira et al. (2003), Pereira e Fortes (2003), Donato et al. (2005) e Naue et al. (2007).

O meio de cultura utilizado foi o MS (MURASHIGE; SKOOG, 1962), suplementado com $20 \mathrm{~g}$ $\mathrm{L}^{-1}$ de sacarose e $7,0 \mathrm{~g} \mathrm{~L}^{-1}$ de ágar, com $\mathrm{pH}$ ajustado para $5,7 \pm 0,1$, antes da autoclavagem a $120^{\circ} \mathrm{C}$ com $1 \mathrm{Kgf} \mathrm{cm}^{-2}$, durante vinte minutos. As doses dos antibióticos correspondentes aos tratamentos foram adicionadas ao meio de cultura após a autoclavagem, dentro da câmara de fluxo laminar, e em seguida foram vertidos $15 \mathrm{~mL}$ do meio nutritivo em tubos de ensaio.

Após coletados em campo, os segmentos de ramos contendo as gemas foram colocados em recipiente com água corrente. Em seguida, as gemas apicais foram seccionadas com bisturi esterilizado, permitindo assim a redução de seu tamanho. Para desinfestação superficial dos explantes, eles foram submetidos a um protocolo previamente estabelecido, realizado fora da câmara de fluxo laminar. Neste caso, foram realizadas as seguintes etapas: $1^{\circ}$ ) os explantes foram imersos em etanol a $70 \%$ durante 1 minuto, lavados 3 vezes com água destilada autoclavada; $2^{\circ}$ ) imersos em uma solução de $2 \mathrm{~g} \mathrm{~L}^{-1}$ de methiltiofan (fungicida) $+250 \mathrm{mg} \mathrm{L}^{-1}$ de cloranfenicol (antibiótico) durante 5 minutos e lavados 3 vezes com água destilada autoclavada; $3^{\circ}$ ) na sequência, os explantes foram imersos durante 5 minutos em $250 \mathrm{mg} \mathrm{L}^{-1}$ de ácido cítrico $+250 \mathrm{mg} \mathrm{L}^{-1}$ de ácido ascórbico, e $\left.4^{\circ}\right)$ imersos em hipoclorito de sódio (2,5\% cloro ativo), sob agitação constante, durante 15 minutos, e sua lavagem foi realizada dentro da câmara de fluxo laminar, em condições assépticas, onde as gemas foram inoculadas ao meio de cultura com os respectivos tratamentos. A fase de estabelecimento foi realizada em sala de crescimento com temperatura 22 $\pm 3{ }^{\circ} \mathrm{C}$, sendo mantidas durante os quatro primeiros dias no escuro, e em seguida, em fotoperíodo de 16 horas de luz a uma intensidade luminosa de $30 \mu \mathrm{mol}$ $\mathrm{m}^{-2} \mathrm{~s}^{-1}$. Os explantes foram avaliados trinta dias após a inoculação. As variáveis avaliadas foram: explantes contaminados por bactérias, oxidados e sobreviventes, cujos valores foram expressos em percentagem.

Os dados obtidos foram transformados em arco-seno $\sqrt{\mathrm{x} / 100}$ de acordo com Banzatto e Kronka (2006), visando à análise de variância. As médias dos tratamentos foram comparadas pelo teste de Duncan, a $5 \%$ de probabilidade.

\section{RESULTADOS E DISCUSSÃO}

Os contaminantes bacterianos manifestaram-se, nos quinze primeiros dias, na base dos explantes e no interior do meio de cultura. A bactéria que se desenvolveu na base dos explantes foi identificada como Serratia spp., pelo Laboratório de análises clínicas São Marcos, localizado no município de Ilha Solteira - SP. Segundo Anahory et al. (1998), espécies do gênero Serratia geralmente são isoladas de plantas, cogumelos, musgos, trato digestivo dos roedores ( $40 \%$ de pequenos mamíferos silvestres são portadores de Serratia sp.), insetos, água e solo. Uma das espécies conhecidas é a S. ficaria, que pode ser isolada de plantas e de insetos e é encontrada em um determinado nicho ecológico, pois está associada à figueira brava (F. glabra), à figueira cultivada e aos insetos que desempenham um papel importante na fertilização dessas plantas.

Não houve contaminação fúngica, provavelmente devido à eficiência da assepsia realizada nos explantes antes da inoculação destes ao meio de cultura. Kumar et al. (1998) também observaram $95 \%$ de eliminação de contaminantes fúngicos em gemas apicais de figueira, através da imersão das gemas em álcool a 70\%, durante 30 segundos, e em seguida em hipoclorito de sódio a 1\%, durante cinco minutos. Cid e Zimmermann (2006) relatam que o uso de compostos químicos, como hipoclorito de sódio, etanol e fungicidas nas doses e tempos certos, podem ser eficientes para o controle da contaminação fúngica em explantes coletados a campo.

Na Tabela 1, são apresentados os efeitos dos tratamentos na redução da contaminação bacteriana, na oxidação e sobrevivência dos explantes.

Para a variável percentagem de contaminação bacteriana, verificou-se que não houve diferença significativa entre os tratamentos $\mathrm{T}_{1}$ (sem antibiótico) e $\mathrm{T}_{5}$ (cefalotina sódica $150 \mathrm{mg} \mathrm{L}^{-1}$ ), os quais propiciaram maior percentagem de contaminação $(51,43 \%$ e $39,14 \%$, respectivamente). Entre os demais tratamentos: $\mathrm{T}_{2}$ (cloranfenicol $30 \mathrm{mg} \mathrm{L}^{-1}$ ); $\mathrm{T}_{3}$ (ampicilina sódica $250 \mathrm{mg} \mathrm{L}^{-1}$ ); $\mathrm{T}_{4}$ (ácido nalidíxico $500 \mathrm{mg} \mathrm{L}^{-1}$ ); $\mathrm{T}_{6}$ (tetraciclina $500 \mathrm{mg} \mathrm{L}^{-1}$ ), e $\mathrm{T}_{7}$ (norfloxacina 400 $\mathrm{mg} \mathrm{L}^{-1}$ ) também não houve diferença significativa (Tabela 1). Pereira et al. (2003), estudando bactérias endofíticas contaminantes da cultura in vitro da batata (Solanun tuberosum), observaram que entre doze antibióticos testados, seis apresentaram algum tipo de controle e, destes, os melhores resultados foram proporcionados pela ampicilina, cloranfenicol, estreptomicina e tetraciclina.

Houve diferenças significativas entre os tratamentos em relação à percentagem de oxidação 
dos explantes, em que os tratamentos $\mathrm{T}_{3}$ (ampicilina sódica $250 \mathrm{mg} \mathrm{L}^{-1}$ ), $\mathrm{T}_{1}$ (sem anibiótico) e $\mathrm{T}_{5}$ (cefalotina sódica $\left.150 \mathrm{mg} \mathrm{L}^{-1}\right)$ apresentaram as menores percentagens de oxidação, $(0 ; 3,58$ e $8,91 \%$, respectivamente) (Tabela 1). A maior percentagem de explantes sobreviventes, após 30 dias de inoculação, ocorreu no tratamento $\mathrm{T}_{3}$ (ampicilina sódica $250 \mathrm{mg}$ $\left.\mathrm{L}^{-1}\right)$, em que $90,69 \%$ dos explantes se mantiveram vivos e em desenvolvimento (Tabela 1).

Os dados obtidos estão de acordo com Pereira e Fortes (2003), que obtiveram os mesmos resultados com relação à toxicidade de antibióticos no cultivo in vitro de explantes de batatas e relatam que a adição de ampicilina sódica no meio de cultura não afetou a sobrevivência e o desenvolvimento dos explantes, mesmo nas mais altas concentrações. Houve cerca de $100 \%$ de sobrevivência dos explantes após 21 dias de cultivo, indicando não haver efeito fitotóxico deste antibiótico para esta cultura. As menores taxas de sobrevivência dos explantes ocorreram na presença de cloranfenicol e tetraciclina, concordando com o observado com os explantes de figueira.

Um dos fatores limitantes ao uso dos antibióticos adicionados ao meio nutritivo, juntamente com o explante, é a fitotoxidez dessas substâncias, principalmente devido ao uso comum de concentrações elevadas. Segundo Cid e Zimmermann (2006), os antibióticos podem afetar os processos sensíveis dentro da bactéria (síntese de proteína, ácidos nucléicos), e como a nível molecular estes processos são parecidos com os da célula vegetal, torna-se necessário ficar atento a problemas de fitotoxicidade, os quais também são uma decorrência da concentração usada.

A tetraciclina é um antibiótico de amplo espectro de ação, mesmo assim seu uso deve ser considerado restrito na cultura de tecidos, justamente pelo alto grau de fitotoxicidade (POLLOCK et al., 1983). A ação fitotóxica ocorre, principalmente, em virtude de distúrbios da síntese proteica e da ação inibitória na síntese de ARNs e ATPs, interferindo, desta forma, nos sistemas energéticos da planta (PRADO FILHO, 1975). De acordo com Pollock et al. (1983), há eficiência no controle de contaminações quando os tratamentos com este antibiótico são feitos durante curtos períodos.

Quanto à fitotoxicidade do cloranfenicol, pode ter ocorrido porque este antibiótico é inibidor da síntese proteica em plantas, podendo, em alguns casos, interferir no desenvolvimento de cloroplastos e mitocôndrias (LEIFERT et al., 1991).

Koneman et al. (2001) citam que antibióticos pertencentes ao grupo dos betalactanos, como a ampicilina e a carbenicilina, as cefalosporinas (cefotaxime, cefaloridine, cefalotina) e a rifampicina são considerados antibióticos de amplo expectro, ativos contra bactérias gram-positivas e negativas, sendo também pouco ou não tóxicos aos cultivos in vitro. Fato esse que se deve, possivelmente, a sua ação sobre sítios específicos da parede celular bacteriana, os quais não ocorrem em células de plantas (POLLOCK et al. 1983).

TABELA 1 - Percentagem de explantes de figueira contaminados por bactérias, oxidados e sobreviventes, submetidas a diferentes antibióticos adicionados ao meio de cultura. Ilha Solteira - SP, 2009.

\begin{tabular}{cccc}
\hline & \multicolumn{3}{c}{ Explantes } \\
\cline { 2 - 4 } Tratamentos & $\begin{array}{c}\text { Contaminação } \\
\text { bacteriana (\%) }\end{array}$ & Oxidados $\mathbf{( \% )}$ & Sobreviventes (\%) \\
\hline $\mathrm{T}_{1}$ & $51,43 \mathrm{a}$ & $3,58 \mathrm{c}$ & $39,78 \mathrm{c}$ \\
$\mathrm{T}_{2}$ & $13,44 \mathrm{~b}$ & $30,82 \mathrm{ab}$ & $51,43 \mathrm{bc}$ \\
$\mathrm{T}_{3}$ & $00,60 \mathrm{~b}$ & $0,00 \mathrm{c}$ & $90,69 \mathrm{a}$ \\
$\mathrm{T}_{4}$ & $00,60 \mathrm{~b}$ & $24,98 \mathrm{ab}$ & $66,50 \mathrm{~b}$ \\
$\mathrm{~T}_{5}$ & $39,14 \mathrm{a}$ & $8,91 \mathrm{bc}$ & $45,05 \mathrm{bc}$ \\
$\mathrm{T}_{6}$ & $05,31 \mathrm{~b}$ & $54,42 \mathrm{a}$ & $34,12 \mathrm{c}$ \\
$\mathrm{T}_{7}$ & $05,00 \mathrm{~b}$ & $51,43 \mathrm{a}$ & $33,50 \mathrm{c}$ \\
\hline
\end{tabular}

* $\mathrm{T}_{1}$ (sem adição de antibiótico); $\mathrm{T}_{2}\left(30 \mathrm{mg} \mathrm{L}{ }^{-1}\right.$ de cloranfenicol); $\mathrm{T}_{3}\left(250 \mathrm{mg} \mathrm{L}^{-1}\right.$ de ampicilina sódica $) ; \mathrm{T}_{4}\left(500 \mathrm{mg} \mathrm{L}^{-1}\right.$ de ácido nalidícico); $\mathrm{T}_{5}\left(150 \mathrm{mg} \mathrm{L}^{-1}\right.$ de cefalotina sódica); $\mathrm{T}_{6}\left(500 \mathrm{mg} \mathrm{L}^{-1}\right.$ de tetraciclina $), \mathrm{e}_{7}\left(400 \mathrm{mg} \mathrm{L}^{-1}\right.$ de norfloxacina $)$. 


\section{CONCLUSÕES}

1-A adição de antibiótico ao meio de cultura é necessária para o controle da contaminação bacteriana em gemas apicais de figueira.

2-A ampicilina sódica, na concentração de $250 \mathrm{mg} . \mathrm{L}^{-1}$, inibe o crescimento de bactérias in vitro, após a inoculação de gemas apicais de figueira, proporcionando mais de $90 \%$ de explantes sobreviventes.

3-Nas dosagens testadas, os antibióticos clorofenicol, ácido nalidícico, tetracicliona e norfloxacina são fitotóxicos para gemas apicais de figueira.

\section{REFERÊNCIAS}

ANAHORY, T.; DARBAS H.; ONGARO, O.; JEANPIERRE, H.; MION, P. Serratia ficaria: amisidentified or unidentified rare cause of human infections in fig tree culture zones. Journal of Clinical Microbiology, Washington, v. 36, p. 3266-3272, 1998.

BANZATTO, D.A.; KRONKA, S.N. Experimentação agrícola. 4. ed. Jaboticabal: FUNEP, 2006. p.41-53.

BARBOSA, W.; CAMPO DALL'ORTO, F.A.; OJIMA, M.; MARTINS, F.P.; BOVI, V.; ASTRO, J.L. Produção de mudas da figueira 'Roxo de Valinhos', através de cultura in vitro. O Agronômico, Campinas, v.44, n.3, p. 6-10, 1992.

BIASI, L.A. Fitotoxicidade de três antibióticos na cultura in vitro de abacateiro. Bragantia, Campinas, v. 54 , n. 2 , p. $251-256,1995$. Nota

BRUM, G.R. Micropropagação de figueira (Ficus carica L.). 2001. 41f. Dissertação (Mestrado em Fitotecnia) - Universidade Federal de Lavras, Lavras, 2001.

CID, L.P.B.; ZIMMERMANN, M.J. A contaminação in vitro de Plantas. Brasília: Embrapa Recursos Genéticos e Biotecnologia, 2006. (Boletim de Pesquisa, 122).
DANTAS, S.; OLIVEIRA, S.; CÂMARA, T. Contaminação microbiana no cultivo in vitro de plantas. In: LUZ, W. C. da (Org.). Revisão anual de patologia de plantas. 10. ed. Passo Fundo: Passo Fundo: RAPP, 2002. v.10, p. 391-407.

DONATO, V.M.T.S.; ANDRADE, A.G.; TAKAKI, G.M.C.; MARIANO, R.L.R.; MACIEL, G.A. Plantas de cana-de-açúcar cultivadas in vitro com antibióticos. Ciência e Agrotecnologia, Lavras, v. 29, n. 1, p. 134-141, 2005.

FACHINELLO, J.C.; HOFFMANN, A.; NACHTIGAL, J.C. (Ed.). Propagação de plantas frutíferas. Brasília: Embrapa Informações Tecnológicas, 2005. $221 \mathrm{p}$.

FAO - Food Agricultural Organization. Disponível em: $<$ http//www.fao.org $>$. Acesso em: 11 dez. 2008.

FRÁGUAS, C.B. Micropropagação e aspectos da anatomia foliar da figueira "Roxo de Valinhos" em diferentes ambientes. 2003. 110f. Dissertação (Mestrado em Fitotecnia) - Universidade Federal de Lavras, Lavras, 2003.

GUERRA, M.P.; COSTA, R.M.B.F.L. Propagação da figueira 'Roxo de Valinhos', através da cultura de meristemas. In: CONGRESSO BRASILEIRO DE FRUTICUlTURA, 9., 1987, Campinas. Anais... Campinas: SBF, 1988. p. 465-467.

KONEMAN, E.W.; ALLEN, S.D.; JANDA, W.M.; SCHRECKENBERGER, P.C.; WINN, W.C. Provas de sensibilidade a agentes antimicrobianos. In: DIAGNÓSTICO microbiológico. São Paulo: Medsi, 2001. p. $795-865$.

KUMAR, V.; RADHA, A.; CHITA, S.K. In vitro plant regeneration of fig (Ficus carica L.) cv. Gular) using apical buds from mature trees. Plant Cell Reports, New York, v. 17, n. 9, p. 717-720, 1998.

LEIFERT, C.; CAMOTTA, H.; WRIGHT, S.M.; WAITES, B.; CHEYNE, V.A.; WAITES, W. M. Elimination of Lactobacillus plantarum, Corynebacterium spp., Staphylococcus saprophyticus and Pseudomonas paucimobilis from micropropagated Hemerocallis, Choisya and Delphinium cultures using antibiotics. Journal of Applied Bacteriology, London, v. 71, n. 4, p. 307-330, 1991. 
MANICA, I. Colheita, embalagem, armazenamento, amadurecimento, composição. In: MANICA, I. et al. (Ed.). Frutas Anonáceas: ata ou pinha, atemólia, cherimólia e graviola. Porto Alegre: Evangraf, 2003. p.469-535.

MURASHIGE, T.; SKOOG, F.A. A revised medium for rapid growth and bioassays with tobacco tissue cultures. Physiologia Plantarum, Copenhagen, v.15, n.3, p.473-497, 1962.

NAUE, C.R.; BENITIZ, L.B.; MEDEIROS, C.V. Eliminação de contaminantes microbianos da cultura de tecidos de Nicotiana tabacum L. In: CONGRESSO INICIAÇÃO CIENTÍFICA, 16., 2007, Pelotas. Resumos... Pelotas: Faculdade de Agronomia Eliseu Maciel, UFPel, 2007. p. 1-5.

PAIVA, P. D.O. Estabelecimento in vitro de estrelícia (Strelitzia reginae Ait.) e controle de oxidação com identificação dos compostos liberados no meio de cultura. 1998. 84 f. Tese (Doutorado em Fitotecnia) - Universidade Federal de Lavras, Lavras, 1998.

PEREIRA, J. E. S.; FORTES, G.R.L. Toxicidade de antibióticos no cultivo in vitro de batata em meios semissólido e líquido. Pesquisa Agropecuária Brasileira, Brasília, v. 38, n. 11, p. 1273-1279, 2003.
PEREIRA, J.E.S.; MATTOS, M.L.T.; FORTES, G.R.L. Identificação e controle com antibióticos de bactérias endofíticas contaminantes em explantes de batata micropropagados. Pesquisa Agropecuária Brasileira, Brasília, v. 38, n. 7, p. 827-834, 2003.

PEREIRA, G.A.; RIBEIRO, B.V.; MARCÍLIO, H. C.; SANTAELLA, M.B. Desinfestação e estabelecimento in vitro de explantes de bananeira 'IAC 2001' em diferentes concentrações de hipoclorito de sódio. Tecnologia \& Ciência Agropecuária, João Pessoa, v. 3 , n. 2 , p. $43-46,2009$.

POLLOCK, K.; BARFIELD, D.G.; SHIELD, R. The toxicity of antibiotics to plant cell culture. Plant Cell Reports, New York, v. 2, p. 36-39, 1983.

PRADO FILHO, L.G. Emprego de antibióticos em agricultura. In: LACAZ, C.S. (Coord.). Antibióticos São Paulo: E. Blucher, 1975. p. 472-509.

SOUZA, A.S.; LEDO, C.A.S.; SILVEIRA, D.G.; SOUZA, F.V.D.; FARIA, G.A.; NETO, H.P.S.; SANTOS SEREJO, J.S.; SILVA, K.M.; COSTA, M.A.P.C.; SOARES, T.L.; JUNGHANS, T.G; ALMEIDA, W.B. Introdução à micropropagação de plantas. Cruz das Almas: Embrapa Mandioca e Fruticultura, 2006. 152p. 